\title{
Non-communicable respiratory disease in Malawi: a systematic review and meta-analysis
}

\author{
Rebecca Nightingale ${ }^{1,2, *}$, Hannah Jary ${ }^{3, *}$, Jamilah Meghji ${ }^{1,2}$, Sarah Rylance ${ }^{1,2}$, Jones Masiye ${ }^{4}$, Hastings \\ Chiumia $^{4}$, Jamie Rylance ${ }^{1,2}$, Kevin Mortimer ${ }^{1, \dagger}$, Maia Lesosky ${ }^{5, \dagger}$
}

1. Liverpool School of Tropical Medicine, Liverpool, UK

2. Malawi Liverpool Wellcome Trust Clinical Research Programme, Blantyre, Malawi

3. Population Health Science Institute, Newcastle University, Newcastle, UK

4. Ministry of Health, Government of Malawi, Malawi

5. Division of Epidemiology \& Biostatistics, School of Public Health \& Family Medicine, University of Cape Town, South Africa

*Joint first authors.

†Joint last authors.

\section{Background}

Abstract

Non-communicable respiratory diseases are important contributors to morbidity and mortality in sub-Saharan African countries such as Malawi.

Aim

To conduct a systematic review of the available literature relating to chronic respiratory disease in Malawi.

Methods

We conducted a systematic protocol-driven literature search of key scientific databases including Scopus and Medline. Papers were independently assessed for eligibility by two authors and included if they reported objective measures (including self-reported standard symptoms) of chronic respiratory disease and were conducted in Malawi. A meta-analysis of available estimates was then conducted. We re-analysed data from three of these studies in a secondary data analysis to allow for between-study comparisons.

Results

Our search identified 393 papers of which 17 (5 involving children and 12 involving adults) met the inclusion criteria. Wheeze was the symptom most frequently reported in children in the community $(12.1 \%)$, hospital $(11.2 \%)$ and HIV clinic $(8.1 \%)$ settings. Cough was the symptom most frequently reported by adults in the community $(3-18 \%)$. Spirometric abnormalities varied substantially between studies. For example, in adults, airflow obstruction varied between $2.3 \%$ and $20 \%$ and low forced vital capacity (FVC) varied between $2.7 \%$ and $52.8 \%$.

Conclusion

We identified a high burden of chronic respiratory symptoms and abnormal spirometry (particularly low FVC) within paediatric and adult populations in Malawi. The estimates for country-wide burden related to this disease were limited by the heterogeneity of the methods used to assess symptoms and spirometry. There is an urgent need to develop a better understanding of the determinants and natural history of non-communicable respiratory disease across the life-course in Malawi.

Key Words: COPD, asthma, chronic lung disease, cough, non-communicable disease, Malawi

\section{Introduction}

Non-communicable diseases (NCDs) kill 41 million people globally, accounting for $71 \%$ of deaths worldwide ${ }^{1}$. More than three quarters (32 million) of these deaths occur in low- and middle-income countries (LMICs), including LMICs in sub-Saharan Africa, such as Malawi. Health policy has historically focussed on communicable rather than non-communicable disease in sub-Saharan African countries $^{2}$, although the need to prioritise the prevention and control of NCDs is increasingly recognised, with the Malawi National Health Research Agenda highlighting the fact that chronic lung disorders are a priority research area for the country ${ }^{3-5}$. Non-communicable respiratory diseases are major contributors to NCD mortality with 3.6 million attributable deaths globally in $2015^{6}$. Of these diseases, asthma and chronic obstructive pulmonary disease (COPD) are the most common $^{7-10}$. The International Study of Asthma and Allergies in Childhood (ISAAC) estimated the prevalence of asthma using standardised questionnaires in 105 countries $^{11}$. In the seven countries from sub-Saharan Africa, the prevalence of asthma varied between $9.1 \%$ in Ethiopia and $20.3 \%$ in South Africa ${ }^{11}$. The prevalence of
COPD has been estimated from cross-sectional spirometrybased studies, including the International Burden of Obstructive Lung Disease (BOLD) initiative ${ }^{12}$. The highest prevalence was seen in Cape Town, South Africa where moderate to severe obstruction was present in $19.1 \%$ of the adult population whilst prevalence in Ile-Ife (Nigeria), urban Blantyre (Malawi) and rural Chikwawa (Malawi) were $7.7 \%, 3.6 \%$ and $8.7 \%$, respectively ${ }^{13-16}$. Recently, two further studies have reported lower levels of obstruction in Uganda: $6.1 \%$ and $2 \%$ in rural populations, and $1.5 \%$ in an urban population ${ }^{17,18}$.

We conducted a systematic review and pooled analysis of the burden of NCDs and the risk factors associated with NCDs in Malawi. This review adopted a broad approach and focused on any population, any intervention, any comparison technique, any outcome, and any study design.

\section{Methods \\ Systematic review}

This systematic review is registered with the Centre for Reviews and Dissemination (Registration number: CRD42018117325). The full protocol is available at http:// 
www.crd.york.ac.uk/prospero.

\section{Eligibility criteria}

Publications were included if they described the burden of non-communicable respiratory diseases (including COPD, asthma, low forced vital capacity (FVC)/ restrictive disease and bronchiectasis) in Malawian individuals of any population (any sex or age), involving any intervention and outcomes linked to non-communicable respiratory disease. We included any form of study design, including studies that defined non-communicable respiratory diseases using symptoms, self-reported diagnosis, doctor diagnosis, and spirometry.

\section{Search strategy}

The databases and grey literature listed in Box 1 were searched using the specific search terms and Boolean phrases listed in Box 2 and the search strategy set out in Box 3. Identified papers were then imported into EndNote X7. The reference lists of all selected papers were also reviewed to identify any potentially eligible titles. For studies where relevant details were not available, authors were invited to supply information if their contact details were available.

\begin{tabular}{l}
\hline Box 1: Databases and Grey Literature \\
Databases: \\
- Scopus (including EMBASE) \\
- MEDLINE (OVID) \\
- Web of Science \\
- Cochrane Central Register of Controlled Trials \\
(CENTRAL) \\
- CINAHL (OVID) \\
- SciELO \\
Grey literature: \\
- World Health Organization Clinical Trials Registry \\
- www.clinicaltrials.gov \\
- European Association for Grey Literature Exploitation \\
(EAGLE)
\end{tabular}

\section{Box 2: Search terms and Boolean phrases used}

Outcomes (OR): "chronic respiratory" OR "non communicable lung" OR "chronic obstructive pulmonary disease" OR "COPD" OR "asthma" OR "obstructive lung" OR "restrictive lung" OR "obstructive respiratory" OR "restrictive respiratory" OR "obstructive airway*" OR "restrictive airway*" OR "spirometr*" OR "wheeze" OR "chronic cough" OR "shortness of breath" OR "breathlessness" OR "chronic sputum"

AND

Location: "Malawi"

\section{Article screening}

Following the removal of duplicates, the titles of all identified papers were independently reviewed for eligibility by two authors (HJ \& RN). Abstracts of the selected titles, and then the full text of the selected articles, were independently reviewed for eligibility by two authors (HJ \& RN), according to the selection criteria. Discordant decisions were resolved by discussion, with final arbitration by a third author.
Box 3: Example search strategy for Medline (OVID)

1. "chronic respiratory".mp,tw.

2. "non-communicable lung".mp,tw.

3. "chronic obstructive pulmonary disease" .mp,tw.

4. COPD.mp,tw.

5. asthma.mp,tw.

6. "obstructive lung" .mp,tw.

7. "restrictive lung".mp,tw.

8. "obstructive respiratory" .mp,tw.

9. "restrictive respiratory".mp,tw.

10. “obstructive airway*”.mp,tw.

11. "restrictive airway*".mp,tw.

12. spirometr*.mp,tw.

13. wheeze.mp,tw.

14. "chronic cough" .mp,tw.

15. "shortness of breath.mp,tw.

16. "breathlessness" .mp,tw.

17. "chronic sputum" .mp,tw.

18. 1 OR 2 OR 3 OR 4 OR 5 OR 6 OR 7 OR 8 OR 9 OR 10 OR 11 OR 12 OR 13 OR 14 OR 15 OR 16 OR 17

19. Malawi.mp,tw.

20. 18 AND 19

$\mathrm{mp}$ is combined search field, tw is title and abstract field

\section{Data extraction}

Data were extracted by $\mathrm{HJ}$ and $\mathrm{RN}$ from the selected papers using a data extraction form (which had been pretested). These forms were used to create summary tables and narrative syntheses. Data extraction was independently checked by ML. We also collated information regarding exposure to household air pollution, smoking and previous TB, where available.

\section{Methodological quality assessment}

The methodological quality of the selected studies was assessed by HJ using the Newcastle-Ottawa Scale for cohort and case-control studies (scored out of 9) and a modified version of the Newcastle-Ottawa Scale for cross-sectional studies (scored out of 5) (Table 1).

\section{Statistical analysis}

Published estimates of the prevalence of symptoms, obstruction or low FVC, and mean (standard deviation [SD]) and median (interquartile range ([IQR]) carbon monoxide (CO), and fine particulate matter $\left(\mathrm{PM}_{25}\right)$ were extracted for meta-analysis. We then created Forest plots using the estimated proportion and 95\% confidence intervals. Metaanalysis estimates of overall prevalence were stratified by age group (adult, paediatric) and estimated using the DerSimonian-Laird random effects model ( $\mathrm{R}$ package metaviz ${ }^{19}$. Estimates derived from meta-analysis were only calculated for outcomes in which the studies were deemed to be adequately homogenous. Estimates of measures of heterogeneity $\left(\mathrm{I}^{2}, \mathrm{tau}^{2}\right)$ and an overall Q-test were generated using linear mixed effects models ( $\mathrm{R}$ package metaphor) and reported. Publication bias was evaluated by visual inspection of funnel plots.

Data from three of the studies included in the meta-analysis that had been performed using the same core BOLD protocol were re-analysed in order to provide comparable estimates: the Adult Lung Health Study (ALHS), the 


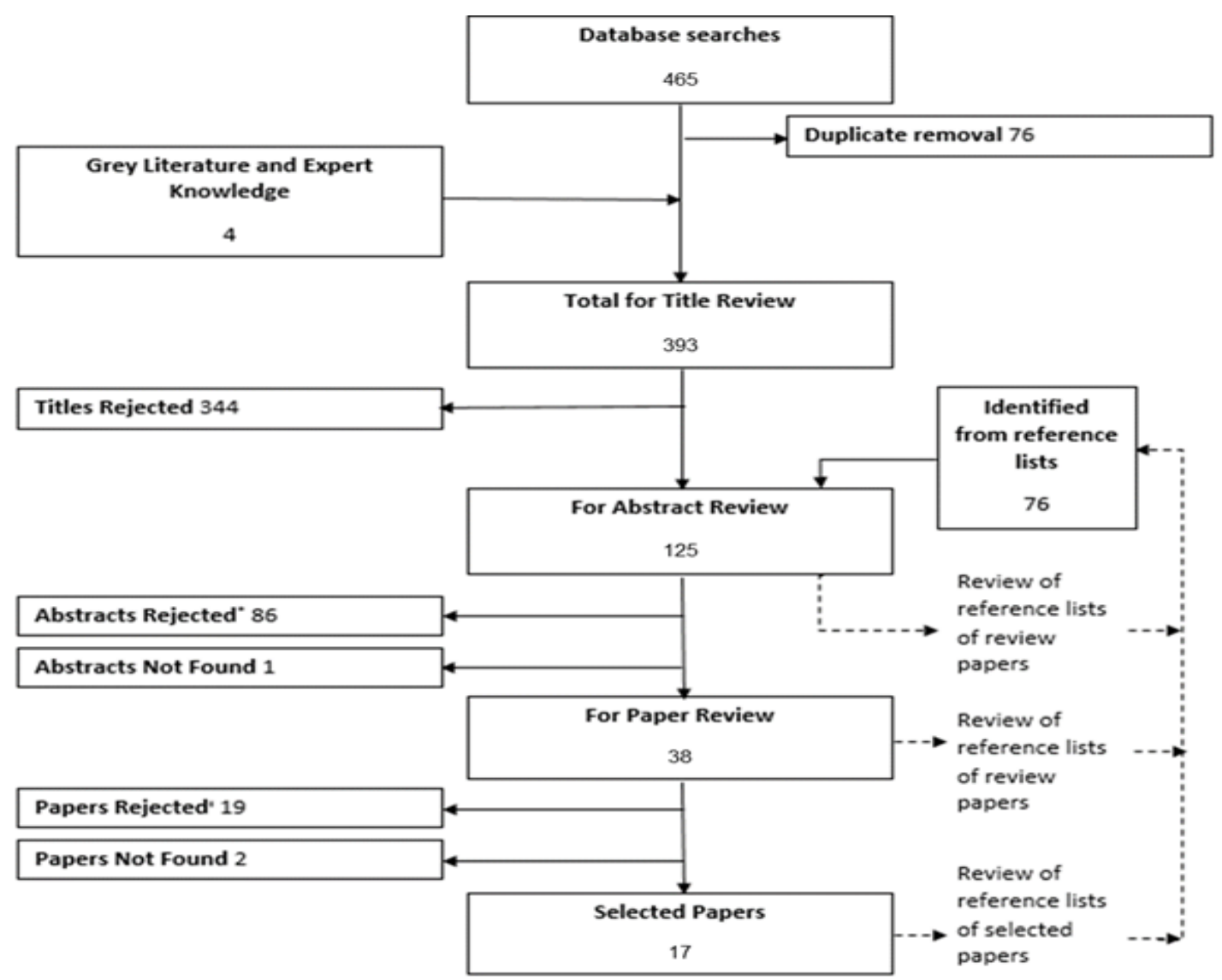

Figure 1: PRISMA Flow Chart depicting the inclusion and inclusion of studies. "Reasons for abstract rejection: no primary data (45), no Malawian data (26), no assessment of non-communicable lung disease (12), duplicate data (2), data not yet available (1). 'Reasons for paper rejection: no Malawian data (9), duplicate data (6), no assessment on non-communicable lung disease (2), data not yet available (1), no primary data (1).
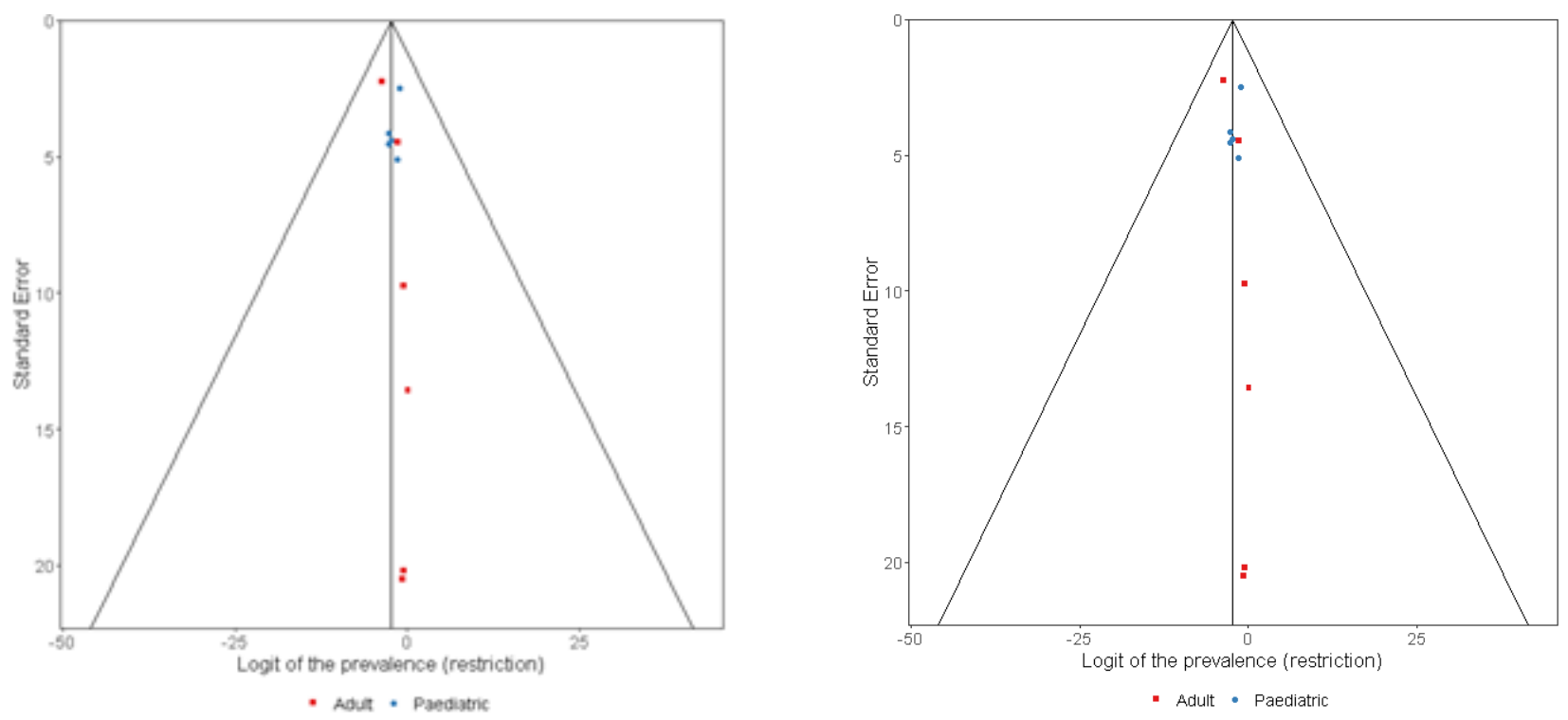

Figure 2. Funnel plots for lung function estimates in paediatric (blue) and adult (red) populations. Panel A (left): restriction, Panel B (right) obstruction.

Blantyre Health Study (BHS), and the Acute Infection of the Respiratory tract Study (AIR Study) $)^{15,16,20}$. This allowed for the pooled analysis of data which had not previously been performed (referred to subsequently as the "pooled analysis" to distinguish this from the "meta-analysis"). Details of the sampling and measurement procedures for these three studies have been described previously; consequently, we restricted our description of these methods to the secondary analysis presented here ${ }^{12,13,15,16,20,21}$. The prevalence (with SD) of symptoms, exposures, obstruction, and low FVC, were estimated using a combination of the three data sources, and is referred to as "pooled data" hereafter. We also calculated median (IQR) estimates for $\mathrm{CO}$ and $\mathrm{PM}_{2.5}$ exposure. 
Table 1. The risk of bias, as determined by the Newcastle-Ottawa Scale

\begin{tabular}{|c|c|c|c|c|}
\hline \multicolumn{5}{|c|}{ Case-control and cohort studies } \\
\hline & $\begin{array}{l}\text { Selection } \\
\text { (out of 4) }\end{array}$ & $\begin{array}{l}\text { Comparability (out } \\
\text { of } 2 \text { ) }\end{array}$ & $\begin{array}{c}\text { NCLD assessment (out } \\
\text { of } 3 \text { ) }\end{array}$ & $\begin{array}{l}\text { Overall score (out } \\
\text { of } 9 \text { ) }\end{array}$ \\
\hline Jary et al., 2017 & 3 & 2 & 2 & 7 \\
\hline Lelijveld et al., 2017 & 3 & 2 & 2 & 7 \\
\hline \multicolumn{5}{|c|}{ Descriptive cross-sectional studies } \\
\hline & $\begin{array}{l}\text { Selection } \\
\text { (out of 3) }\end{array}$ & \multicolumn{2}{|c|}{$\begin{array}{c}\text { NCLD assessment } \\
\text { (out of 2) }\end{array}$} & $\begin{array}{l}\text { Overall score (out } \\
\text { of } 5 \text { ) }\end{array}$ \\
\hline Zverev et al., 2001 & 1 & \multicolumn{2}{|r|}{2} & 3 \\
\hline Fullerton et al., 2011 & 2 & \multicolumn{2}{|r|}{2} & 4 \\
\hline To et al., 2012 & 2 & \multicolumn{2}{|r|}{1} & 3 \\
\hline Cook et al., 2013 & 1 & \multicolumn{2}{|r|}{2} & 3 \\
\hline Jary et al., 2014 & 1 & \multicolumn{2}{|r|}{0} & 1 \\
\hline Manjomo et al., 2016 & 2 & \multicolumn{2}{|r|}{0} & 2 \\
\hline Meghji et al., 2016 & 2 & \multicolumn{2}{|r|}{2} & 4 \\
\hline Mwalukomo et al., 2016 & 1 & \multicolumn{2}{|r|}{2} & 3 \\
\hline Wang et al., 2016 & 0 & \multicolumn{2}{|r|}{0} & 0 \\
\hline Banda et al., 2017 & 2 & \multicolumn{2}{|r|}{1} & 3 \\
\hline Das et al., 2017 & 1 & \multicolumn{2}{|r|}{1} & 2 \\
\hline Townend et al., 2017 & 1 & \multicolumn{2}{|r|}{2} & 3 \\
\hline Cohen et al., 2019 & 1 & \multicolumn{2}{|r|}{1} & 2 \\
\hline Nightingale et al., 2019 & 2 & \multicolumn{2}{|r|}{2} & 4 \\
\hline Rylance et al., 2019 & 2 & \multicolumn{2}{|r|}{2} & 4 \\
\hline
\end{tabular}

\section{Ethics}

Liverpool School of Tropical Medicine provided ethical approval for all three studies which we included for secondary data analysis (Reference numbers: 12.08, 12.40 and 14.016). The ALHS and AIR were approved by the College of Medicine Research and Ethics Committee, Malawi (References: p.11/12/1308 and P.02/14/1518, respectively), and the BHS was approved by the National Research and Ethics Committee of Malawi (Reference: 12.08). All participants provided informed consent.

\section{Results}

\section{Study selection}

Database and grey literature searches on 9 October 2018 and updated on 3 June 2019 identified 393 titles for review; 17 papers met the inclusion criteria (Figure 1) ${ }^{15,16,20,22-35}$. Funnel plots were limited by the small number of studies but were relatively symmetrical $(P=0.017$ for obstruction and $P=0.032$ for restriction, as determined by the Eager test) (Figure 2).

\section{Quality assessment}

Analyses showed that the included studies were of variable quality. Studies that had been specifically designed to assess the burden of non-communicable respiratory disease were found to be of the highest quality (Table 1).

\section{Study characteristics}

The studies incorporated cohort $(n=1)^{25}$, case-control $(n=1)^{20}$, and cross-sectional $(n=15)$ study designs (or included a cross-sectional description of non-communicable respiratory disease burden nested within a Randomised Control Trial or economic evaluation) (Table 2). Five studies reported paediatric populations ${ }^{22-26}$, while 12 reported adult populations ${ }^{15,16,20,27-35}$; one of the studies included a population from 10 to 65 years of age (Table 2$)^{31}$. Nine studies were from urban settings only (four healthcare or clinic-based, three community-based, and the case-control and cohort studies were performed in both community and health care settings $)^{16,20,22-25,30,35}$, five were from rural settings only (all community-based) 15,26,29,31,32,34, and three studies incorporated both rural and urban settings (all communitybased $)^{27,28,33}$.

\section{Symptoms}

Thirteen studies assessed self-reported respiratory symptoms or diagnoses using questionnaires; of these, five used BOLD questionnaires ${ }^{15,16,20,23,24,26-29,31-34}$ (Table 3).

In the paediatric population, the most commonly reported symptom in the community was wheeze, with a prevalence of $12.1 \%$, followed by cough (prevalence $8 \%)^{24}$. In the two studies related to the prevalence of symptoms in hospital clinics, cough was more common (41.7\% and $37.5 \%)$ than wheeze $(11.2 \% \text { and } 8.1 \%)^{23,24}$. Our meta-analysis estimated that the prevalence of cough symptoms in children was $29.1 \pm 10.6\left(P=0.0059, I^{2}=98 \%\right.$, Q-test $\left.P<0.0001\right)$ (Figure 3). Within the adult populations in the community, cough was the most commonly reported symptom (range: 3-18.6\%), followed by shortness of breath (range: 1.6-13\%). Productive cough and phlegm production were less commonly reported (range: $0.2-9 \%$ and $1.4-5.9 \%$ respectively). Our metaanalysis and pooled analysis estimates for prevalence of cough symptoms in adults were $13.3 \pm 10.6 \%, P<0.0001$, 

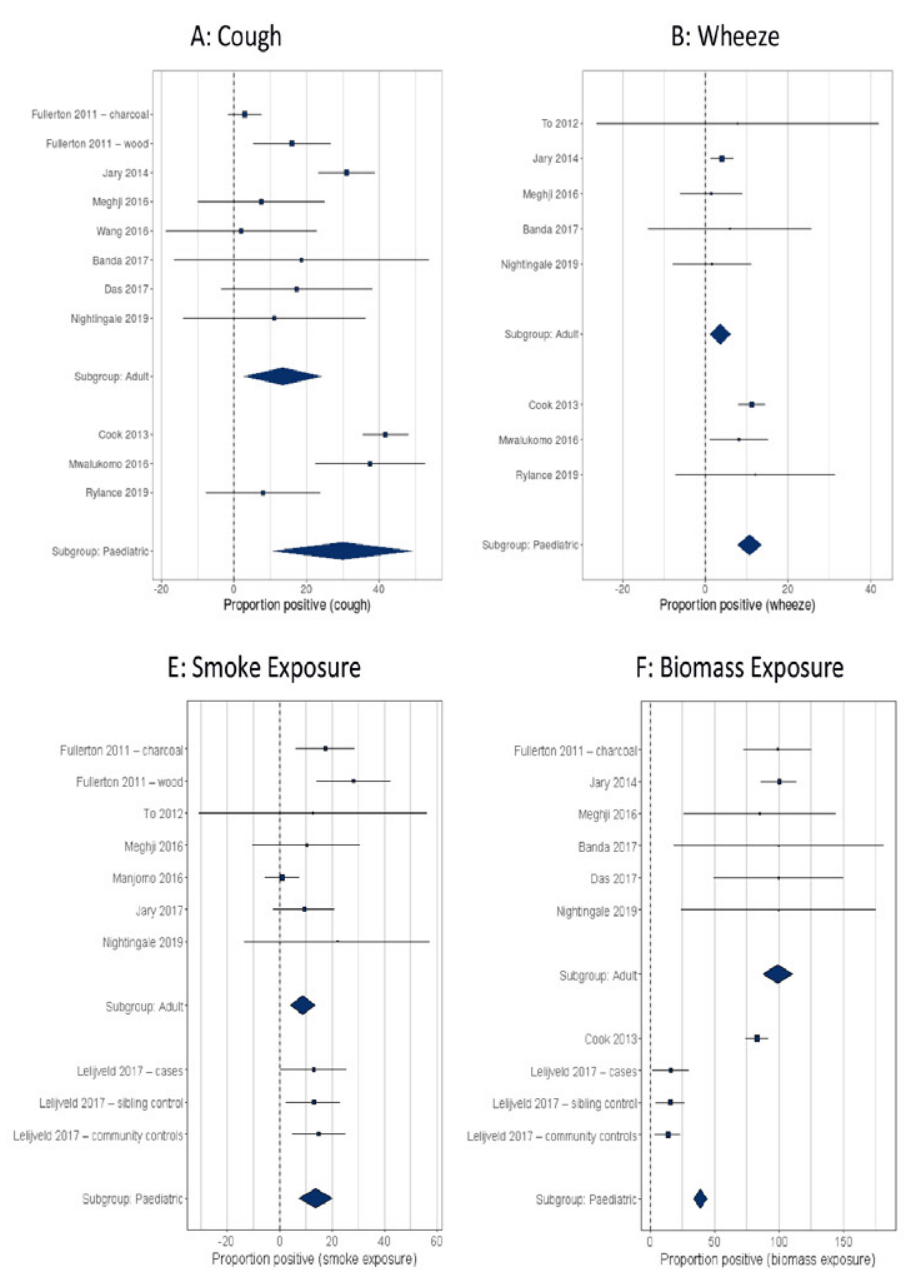
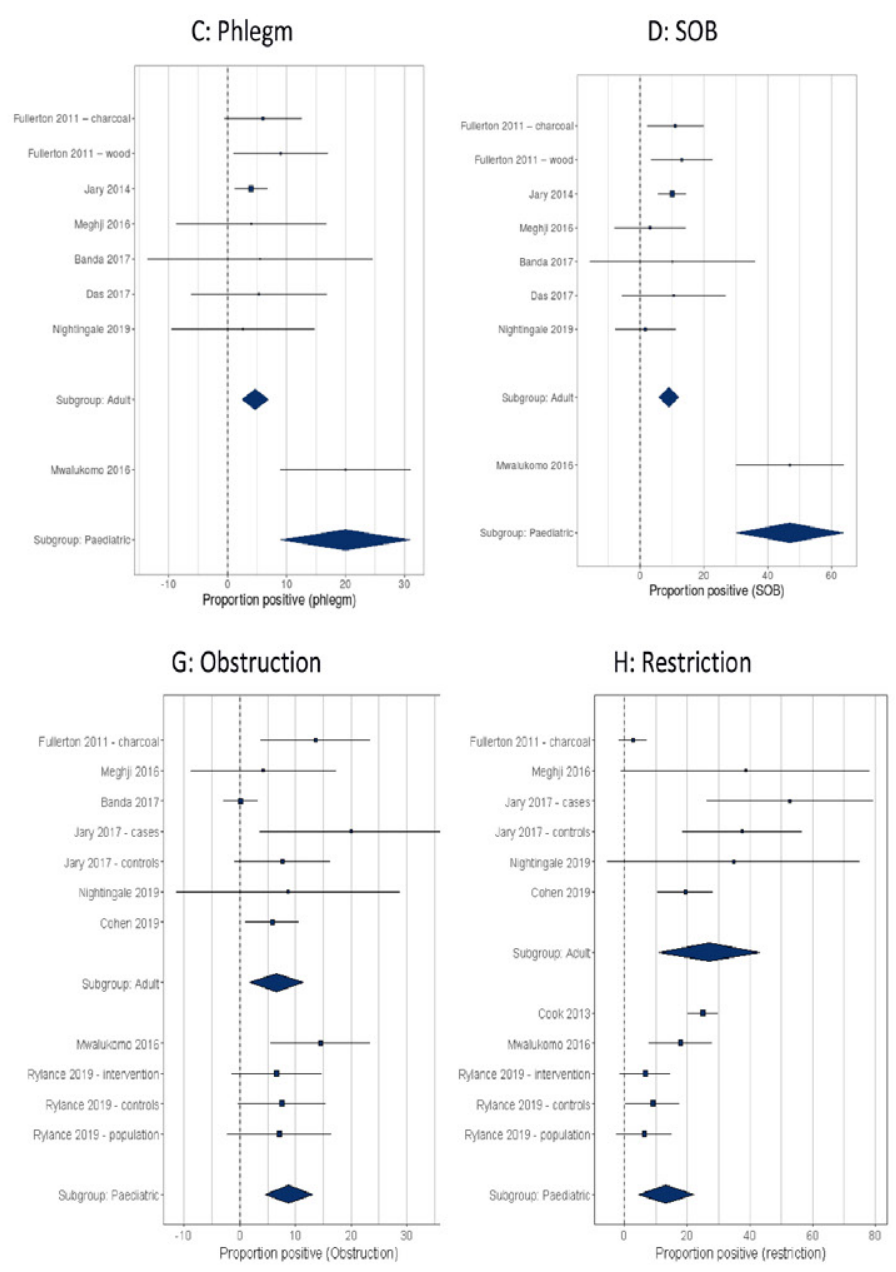

Figure 3. Forest plots and meta-analysis estimates for symptoms (A-D), exposure (E, F) and respiratory outcomes (G, H ). SOB: shortness of breath.

$\mathrm{I}^{2}=93 \%$, Q-test $P<0.0001$ ) and $10.7 \%$, respectively (Figure 3).

\section{Lung function}

Eight of the nine studies (four paediatric and four adult) that performed spirometry reported data that were collected in accordance with standards reported by the American Thoracic Society (ATS)/European Respiratory Society (ERS). However, five different ranges were used and a mix of raw values, proportional (\%) predicted values and Z-scores were used in analysis 20,23-27,33-35 $^{\text {(Table 4). }}$

One study, a community-based cross-sectional study, focused on peak expiratory flow rate (PEFR) in stunted children, reported that PEFR was reduced in those with poor growth ${ }^{20}$. In paediatric community populations, 6.6$9.0 \%$ of the population had obstruction while $6.6-7.5 \%$ had low FVC. In those with sickle cell disease and HIV infection, obstructive spirometry was identified in 0 and $18 \%$ of cases while low FVC was detected in $25 \%$ and $17 \%$ of cases, when using local reference ranges $(58 \%$ and $20 \%$ if using international reference ranges), respectively ${ }^{23,24}$. The cohort study that assessed lung function in malnourished children reported a reduced $\mathrm{FEV}_{1}$ (forced expiratory volume in the first second) and FVC in all study groups, but with no significant difference between paediatric survivors of severe acute malnutrition and healthy controls ${ }^{25}$. The diagnosis of asthma in children, based on spirometry and questionnaires, was reported in $3.9 \%$ of the community or $12.1 \%$ if wheeze was used as the definition; asthma was also reported in $4.2 \%$ of children with sickle cell anaemia ${ }^{23,26}$. None of the studies used the same definition for asthma in the same way. The range of obstruction reported in adults where spirometry had been completed was 2.3-20\% with low FVC varying from $2.7 \%$ to $52.8 \% \%^{20,27}$. The use of different ranges within the same population resulted in a prevalence of obstruction of $2.3-4.2 \%$, and low FVC of $9-38.6 \%$, using local and NHANES (National Health and Nutrition Examination Survey) Caucasian ranges, respectively ${ }^{15,16}$. The prevalence of asthma in adults ranged from $0 \%$ to $12.2 \%$ with a mixture of diagnostic types: doctor diagnosis (7.6-12.2\%), self-reported $(4.7-8 \%)$ and diagnoses involving spirometry $(0-4.2 \%)^{16,18,25,26,28,30-32}$. In our meta-analysis, the prevalence of obstruction in adults was $8.3 \pm 2.4 \%, P=0.0007, \mathrm{I}^{2}=$ $89 \%$, Q-test $P<0.0001$ ), and low FVC 31 $47.2 \%, P<0.0001$, $\mathrm{I}^{2}=97 \%$, Q-test $P<0.0001$ (Figure 2). Pooled analysis estimated overall $\mathrm{FEV}_{1}$ of $2.64 \mathrm{~L}(0.69)$, FVC of $3.28 \mathrm{~L}(0.77)$ and FEV1/FVC of $80.5 \%$ (8.48). The pooled prevalence of obstruction was $8.4 \%$ and low FVC was $37.5 \%$ (NHANES) or $16.3 \%$ (using the local range).

\section{Risk factors}

The most commonly reported risk factors for noncommunicable respiratory disease were the use of biomass fuel and smoking. Exposure to biomass fuel was assessed in a variety of different ways in different studies. In paediatric studies, $14-83 \%$ of the study populations were exposed to biomass fuels ${ }^{23,25}$ (Table 3). In adult studies, self-reported exposure to biomass fuel was reported in 
Table 2. Summary of the main findings from literature searches (date order)

\begin{tabular}{|c|c|c|c|c|c|c|}
\hline Author (year) & Year & Rural/Urban & $\begin{array}{c}\text { Mean } \\
\text { Age } \\
\text { (years) }\end{array}$ & Setting and study design & Sample size & Assessment methods \\
\hline \multicolumn{7}{|l|}{ Paediatric } \\
\hline Zverev & 2001 & Urban & & $\begin{array}{l}\text { Children in primary school, children from each class were randomly } \\
\text { selected }\end{array}$ & 539 & $\begin{array}{l}\text { Peak expiratory flow } \\
\text { only. No symptoms } \\
\text { questionnaires. No } \\
\text { spirometry }\end{array}$ \\
\hline Cook & 2013 & Urban clinic & 11.5 & Consecutive recruitment from paediatric Sickle Cell Anaemia Clinic & 25 & $\begin{array}{l}\text { Self-reported respiratory } \\
\text { symptoms (ISACC } \\
\text { questionnaire) and } \\
\text { spirometry. }\end{array}$ \\
\hline Mwalukomo & 2016 & Urban clinic & 11.1 & $\begin{array}{l}\text { First } 3 \text { eligible patients at paediatric HIV clinic per day were } \\
\text { recruited }\end{array}$ & 160 & $\begin{array}{l}\text { Self-reported respiratory } \\
\text { symptoms and clinical } \\
\text { observation and spirometry }\end{array}$ \\
\hline Lelijveld & 2017 & Urban hospital & & $\begin{array}{l}\text { Cases: consecutive patients admitted with severe acute malnutrition } \\
\text { in 2006-2007. Sibling controls: closest in age to case. Community } \\
\text { controls: random direction selected from case home then door-to- } \\
\text { door recruitment (age- \& sex-matched). }\end{array}$ & $\begin{array}{l}320 \text { cases (of } 477 \text { alive } 1 \\
\text { year after original discharge); } \\
217 \text { sibling controls; } 184 \\
\text { community controls }\end{array}$ & Spirometry \\
\hline Rylance & 2019 & Rural & 7.1 & Population sampling with control and intervention arm & $\begin{array}{l}804 \text { including } 476 \text { ( } 260 \\
\text { intervention and } 216 \text { control) } \\
\text { from CAPS households }\end{array}$ & $\begin{array}{l}\text { Self-reported respiratory } \\
\text { symptoms (BOLD } \\
\text { questionnaire) and } \\
\text { spirometry }\end{array}$ \\
\hline \multicolumn{7}{|l|}{ Adult } \\
\hline Fullerton & 2011 & Rural/urban & 39 & $\begin{array}{l}\text { Cross-sectional survey. Rural: first household semi-randomly } \\
\text { selected, then snowballing sampling strategy. } \\
\text { Urban: randomly selected from } 360 \text { research volunteers, then } \\
\text { snowballing sampling strategy. } \\
\text { Biased selection toward women }\end{array}$ & 374 & $\begin{array}{l}\text { Self-reported respiratory } \\
\text { symptoms and diagnoses } \\
\text { and spirometry. }\end{array}$ \\
\hline To & 2012 & Rural/urban & & Multi-stage cluster design: random & 3890 & $\begin{array}{l}\text { Self-reported respiratory } \\
\text { symptoms and diagnoses } \\
\text { and self-reported doctor } \\
\text { diagnosed. }\end{array}$ \\
\hline Jary & 2014 & Rural & 35 & $\begin{array}{l}\text { Community based survey of women wishing to purchase a } \\
\text { cookstove - not randomly selected. }\end{array}$ & 51 & $\begin{array}{l}\text { Self-reported respiratory } \\
\text { symptoms. }\end{array}$ \\
\hline Meghija & 2016 & Urban & 42 & $\begin{array}{l}\text { Random sample from enumerated population - age- and sex- } \\
\text { stratified population-representative sample. }\end{array}$ & 1059 (of 1240 eligible) & $\begin{array}{l}\text { Self-reported respiratory } \\
\text { symptoms (BOLD } \\
\text { questionnaire) and } \\
\text { spirometry. }\end{array}$ \\
\hline Manjomo & 2016 & Urban & & $\begin{array}{l}\text { All patients registered with NCDs attending a chronic care clinic at a } \\
\text { primary health care centre. }\end{array}$ & 1135 & Diagnosis of asthma at clinic \\
\hline Wang & 2016 & Rural & & $\begin{array}{l}\text { Cross sectional survey, from three districts. Sampling method } \\
\text { unclear. Paediatric adult overlap with participant 10-65 years old. }\end{array}$ & $\begin{array}{l}5643 \text { individuals from } 1199 \\
\text { households }\end{array}$ & $\begin{array}{l}\text { Self-reported chronic } \\
\text { respiratory symptoms } \\
\text { reported as a group }\end{array}$ \\
\hline Banda & 2017 & Rural & 36 & $\begin{array}{l}\text { Population proportional sampling using electronic satellite maps: } \\
30 \text { villages randomly selected from each cluster ( } 27 \text { health centre } \\
\text { catchment population), } 7 \text { households randomly selected from each } \\
\text { village. }\end{array}$ & $\begin{array}{l}15795 \text { individuals from } 6304 \\
\text { households with } 1728 \text { who } \\
\text { had health passports checked } \\
\text { for symptoms }\end{array}$ & $\begin{array}{l}\text { Self-reported respiratory } \\
\text { symptoms / health passport } \\
\text { assessment of symptoms. }\end{array}$ \\
\hline Das & 2017 & Rural/peri-urban & 37.3 & Random sample of households from representative villages. & $\begin{array}{l}655 \text { households ( } 382 \text { rural, } \\
273 \text { peri-urban). }\end{array}$ & $\begin{array}{l}\text { Self-reported respiratory } \\
\text { symptoms. }\end{array}$ \\
\hline
\end{tabular}

aFrom the same study population.

$51-100 \%$ of the study populations ${ }^{29,34}$. The self-reported prevalence of smoking ("ever smoked") ranged from $1 \%$ to $28.2 \%$ in the adult population ${ }^{27,30}$. Previous TB and low BMI were considered as possible risk factors in the BOLD studies. Meta-analysis and pooled analysis of associations between risk factors and lung function was not possible due to the incomplete nature of reporting across different studies ${ }^{15,16,20,34}$. 
Table 3. Extracted proportions (\%) of cases showing symptoms and specific exposures (where reported). Empty cells indicate not reported.

\begin{tabular}{|c|c|c|c|c|c|c|c|}
\hline \multirow[t]{2}{*}{ Author (year) } & \multicolumn{4}{|c|}{ Symptoms (\%) } & \multicolumn{3}{|c|}{ Exposures (\%) } \\
\hline & Cough & Wheeze & Phlegm & SOB & Previous TB & Ever Smoked & Biomass \\
\hline \multicolumn{8}{|l|}{ Paediatric } \\
\hline \multicolumn{8}{|l|}{ Zverev at al., 2001} \\
\hline Cook 2013 & 41.7 & 11.2 & & & & & 83 \\
\hline Mwalukomo 2016 & 37.5 & 8.1 & 20 & 46.9 & & & \\
\hline \multirow[t]{3}{*}{ Lelijveld 2017} & & & & & 5 & $13^{d}$ & $16^{d}$ \\
\hline & & & & & 0.6 & $13^{d}$ & $16^{d}$ \\
\hline & & & & & 0.8 & $15^{d}$ & $14^{d}$ \\
\hline Rylance 2019 & 8 & 12.1 & & & 0.4 & & \\
\hline \multicolumn{8}{|l|}{ Adult } \\
\hline \multirow[t]{2}{*}{ Fullerton 2011} & 3 & & 6 & 11 & & 17.5 & 99 \\
\hline & 16 & & 9 & 13 & & 28.2 & \\
\hline To 2012 & & 7.8 & & & & $12.7^{b}$ & \\
\hline Jary 2014 & 31 & 4 & 4 & 10 & & & 100 \\
\hline Meghji 2016d & 7.5 & 1.4 & 4.0 & 3.1 & 2.9 & 10.4 & 85.2 \\
\hline Manjomo 2016 & & & & & & 1 & \\
\hline Wang et al., 2016 & $2.0^{c}$ & & & & & & \\
\hline Banda 2017 & 18.6 & 5.9 & 5.5 & 10.1 & & & 100 \\
\hline Das 2017 & 17.3 & & 5.3 & 10.5 & & & 100 \\
\hline Jary 2017 & & & & & & 9.3 & \\
\hline Townend 2017 & & & & & 5 & 17 & $51^{a}$ \\
\hline \multicolumn{8}{|l|}{ Cohen 2019} \\
\hline Nightingale 2019 & 11.1 & 1.6 & 2.6 & 1.6 & 3.2 & 22.1 & 99.8 \\
\hline $\begin{array}{l}\text { Secondary analysis } \\
\text { from Malawi (pooled } \\
\text { data 2019) }\end{array}$ & 10.7 & 2.2 & 4.0 & 3.2 & 4.1 & 17.7 & 92.8 \\
\hline
\end{tabular}

${ }^{a}$ Open fire for $>20$ years. ${ }^{b}$ Africa region estimate. ${ }^{\circ}$ Chronic symptoms combined. IIndoor tobacco/biofuel use. SOB: shortness of breath.

Table 4. Summary extracted spirometry (FEV1, FVC) or obstruction/low FVC where available. Blank cells indicate data that were not reported.

\begin{tabular}{|c|c|c|c|c|c|c|c|c|}
\hline Author (year) & Group/subgroup & \begin{tabular}{|l} 
Asthma \\
$(\%)$
\end{tabular} & $\begin{array}{l}\text { Low FVC } \\
(\%)\end{array}$ & $\begin{array}{l}\text { Obstruction } \\
(\%)\end{array}$ & \begin{tabular}{|l} 
Reference \\
range
\end{tabular} & \begin{tabular}{|l|} 
FEV1, L \\
Mean (SD)
\end{tabular} & \begin{tabular}{|l|} 
FVC, L \\
Mean (SD)
\end{tabular} & $\begin{array}{l}\text { FEV1/FVC \% } \\
\text { Mean (SD) }\end{array}$ \\
\hline \multicolumn{9}{|l|}{ Paediatric } \\
\hline Zverev et al 2001 & School children & & & & & & & \\
\hline \multirow[t]{2}{*}{ Cook 2013} & \multirow[t]{2}{*}{ Clinic } & & 25 & 0 & Local & $1.45(0.54)$ & $1.68(0.58)$ & $86(2.09)$ \\
\hline & & & 58 & 0 & Wang & $-1.64^{\mathrm{a}}$ & $-1.49^{\mathrm{a}}$ & $-0.39^{\mathrm{a}}$ \\
\hline \multirow[t]{2}{*}{ Mwalukomo 2016} & \multirow[t]{2}{*}{ Clinic-HIV infected } & & 20 & 17.9 & GLI & $-1.31^{\mathrm{a}}$ & $-0.89^{\mathrm{a}}$ & $-0.27^{\mathrm{a}}$ \\
\hline & & & 17.2 & 12.4 & Local & $92.2^{b}$ & $93.9^{b}$ & $87.9^{\mathrm{b}}$ \\
\hline \multirow[t]{3}{*}{ Lelijveld 2017} & Cases-clinic & & & & GLI & $-0.47(1.1)^{\mathrm{a}}$ & $-0.32(1.0)^{a}$ & $-0.21(0.9)^{\mathrm{a}}$ \\
\hline & Controls - siblings & & & & GLI & $-0.48(1.0)^{a}$ & $-0.38(1.1)^{a}$ & $-0.15(0.9)^{\mathrm{a}}$ \\
\hline & Controls - population & & & & GLI & $-0.34(1.1)^{\mathrm{a}}$ & $-0.15(1.1)^{\mathrm{a}}$ & $0.16(1.0)^{\mathrm{a}}$ \\
\hline \multirow[t]{3}{*}{ Rylance 2019} & Intervention & 4.2 & 6.6 & 6.6 & GLI & $-0.41(0.92)^{a}$ & $-0.22(0.77)^{a}$ & $-0.4(0.91)^{\mathrm{a}}$ \\
\hline & Controls & 4.6 & 9.0 & 7.5 & GLI & $-0.60(0.97)$ & $-0.44(0.98)^{a}$ & $-0.34(0.93)^{\mathrm{a}}$ \\
\hline & Population & 3.9 & 6.3 & 7.1 & $\overline{G L I}$ & $-0.48(0.93)$ & $-0.30(0.96)$ & $-.038(0.90)$ \\
\hline
\end{tabular}


Table 4 Cont...

\begin{tabular}{|c|c|c|c|c|c|c|c|c|}
\hline \multicolumn{9}{|l|}{ Adult } \\
\hline Fullerton 2011 & Charcoal users & 7 & 2.7 & 13.6 & $\begin{array}{l}\text { Knudsen \& } \\
\text { asthma self- } \\
\text { reported }\end{array}$ & $2.78(0.68)$ & $3.49(0.87)$ & $79.8(7.5)$ \\
\hline To 2012 & Population & 4.7 & & & & & & \\
\hline Jary 2014 & $\begin{array}{l}\text { Women cooking on } \\
\text { cookstoves }\end{array}$ & & & & & & & \\
\hline \multirow[t]{2}{*}{ Meghji 2016} & \multirow[t]{2}{*}{ Population } & \multirow[t]{2}{*}{4.2} & 38.6 & 4.2 & NHANES & & & \\
\hline & & & 9 & $2.3^{\wedge}$ & Local & & & \\
\hline Manjomo 2016 & Clinic & 12.2 & & & & & & \\
\hline Wang et al 2016 & Population & & & & & & & \\
\hline Banda 2017 & $\begin{array}{l}\text { Population reporting } \\
\text { respiratory symptoms }\end{array}$ & 7.6 & & 0.15 & $\begin{array}{l}\text { Medical } \\
\text { Diagnosis } \\
\text { only }\end{array}$ & & & \\
\hline \multirow[t]{2}{*}{ Das 2017} & $\begin{array}{l}\text { Women cooking on } \\
\text { biomass }\end{array}$ & & & & & & & \\
\hline & Wood users & 8 & & & & $2.43(0.67)$ & $3.19(0.83)$ & $76.5(9.1)$ \\
\hline \multirow[t]{2}{*}{ Jary 2017} & Cases - clinic & 0 & 52.8 & 20 & NHANES & $2.73(0.69)$ & & \\
\hline & Controls & 0 & 37.5 & 7.6 & NHANES & $2.48(0.68)$ & & \\
\hline Townend 2017 & Population & 5 & & & NHANES & & & $78(8)$ \\
\hline Cohen 2019^ & $\begin{array}{l}\text { TB re-treatment patients } \\
\text { at hospital }\end{array}$ & & 19.4 & 5.83 & NHANES & & & \\
\hline Nightingale 2019 & Population & & 34.8 & 8.7 & NHANES & & & \\
\hline $\begin{array}{l}\text { Secondary analysis from } \\
\text { Malawi pooled data } 2019\end{array}$ & Population & & $\begin{array}{l}16.3 \text { (Local) } \\
37.5 \\
\text { (NHANES) }\end{array}$ & 8.4 & NHANES & $2.64(0.69)$ & $3.28(0.77)$ & $80.5(8.48)$ \\
\hline
\end{tabular}

\section{Discussion}

We conducted a systematic review, secondary data analysis, and meta-analysis, of studies relating to non-communicable respiratory disease in Malawi. We identified 17 papers of variable quality with scores on the Newcastle-Ottawa scale ranging from 0 to $7^{15,16,20,22-34}$. Five of these studies related to children while 12 of the studies involved adult populations. In children we found that the main symptom was wheeze, with low FVC being reported in $6.3-20 \%$ of the population; obstruction was reported in $7.1-17.9 \%$ of the study population $^{22-26}$. In adults, we identified a high burden of lung disease, with cough being the most reported symptom. In studies that used spirometry as an outcome measure, over $40 \%$ of the population showed abnormal spirometry results $15,16,20,27$. Low FVC was the most common abnormal spirometry finding, with a pooled population estimate of $37.5 \%$ using NHANES Caucasian reference ranges. We also identified a high prevalence of exposure to biomass fuel $(50-100 \%)$ and a smoking prevalence of $1-21 \% 0^{27,29,30,34}$.

Few studies in the published literature have reported chronic respiratory symptoms and spirometry data from subSaharan African populations. However, the findings from our present systematic review and meta-analysis, which focussed on Malawi, are consistent with data arising from other sub-Saharan African countries. Data from the ISAAC study sites indicated that wheeze occurs in $5-16 \%$ of children in sub-Saharan Africa, with nearly a half of these children exhibiting severe symptoms ${ }^{11}$. On a global basis, wheeze has been reported to occur in $0.8-32.6 \%$ of young children (aged 6-7 years and 2.4-37.6\% in older children (age 13-14 years) ${ }^{11}$. In adults, cough was the most common symptom described in studies from sub-Saharan Africa; BOLD studies in Nigeria reported a prevalence of cough that was $9.7 \%{ }^{36}$. The prevalence of obstruction was lower in Malawi than that found in both Cape Town (19.1\%) and in rural Uganda (16.2\%), although tobacco smoking was more common in both these populations than in Malawi ${ }^{13,37}$. Two recent studies from Uganda found that the prevalence of obstruction was $2-6.1 \%$ and $2 \%$ in a rural setting and $1.5 \%$ in an urban setting; these figures are more in line with the data highlighted in the present review ${ }^{18,17}$. The high prevalence of low FVC that was evident in Malawi was similar to that seen in Nigeria and other resource-poor settings. However, there is limited a limited body of literature relating to the possible causes of low FVC in adults residing in sub-Saharan Africa ${ }^{36}$. The major strength of this study is that it is the first systematic review and meta-analysis of chronic non-communicable respiratory disease in Malawi and provides a significant enhancement to the growing body of evidence highlighting the high burden of lung disease seen within Malawi and the wider sub-Saharan African region. Our work brings together studies of both paediatric and adult populations from diverse settings in Malawi and includes a secondary analysis of data in order to provide new estimates for the pooled burden of disease. The estimates given within this paper https://doi.org/10.4314/mmj.v32i2.3 
are, however, limited by inconsistent methodologies. The studies we reported herein were carried out across a range of populations, from the community setting to subgroups within an acute clinic. The paediatric data described herein are particularly limited because only one paediatric study reported lung function in community settings; the other studies related to specific populations, such as children with sickle cell disease. Furthermore, symptoms were not reported in a consistent or standardised manner. Cough, wheeze, exertional dyspnoea, and the production of sputum, were the most common symptoms reported although there was widespread inconsistency in the definitions used for these symptoms. All symptoms were self-reported; in studies without other diagnostic tools, this inevitably reduced the specificity of diagnosis. Diagnosis of COPD and asthma were made using a combination of clinical or self-reported diagnoses and spirometry. This is likely to explain the wide variation seen in categorising the burden of disease in Malawi. All spirometry data were reported in accordance with ATS standards. However, studies used different interpretative strategies with raw FEV1 and FVC being the most common parameters provided for adult populations and Z-scores the most common parameter for the paediatric population. This lack of standardised reporting also created uncertainty with regards to the estimation of disease burden in Malawi and resulted in high heterogeneity with regards to the metaanalysis estimates. As there is no validated reference range for spirometry in sub-Saharan African populations, a variety of reference ranges were used in the studies reported here. The majority of paediatric studies used the Global Lung Function Initiative (GLI) reference ranges while the majority of adult studies used the NHANES Caucasian reference ranges. However, the NHANES Caucasian reference ranges are also known to be associated with limitations, including the potential overestimation of the prevalence of low FVC; however, this reference range does allow for comparison with other studies, including BOLD studies (the largest, multinational study of spirometry findings thus far). Previous studies have also published results that were interpreted with local (unvalidated) reference ranges.

\section{Conclusion}

In conclusion, we identified a high burden of chronic respiratory symptoms and abnormal spirometry data (particularly low FVC) in children and adults in Malawi. Estimates for the country-wide burden of disease were limited by the heterogeneity of the methods used to assess symptoms and spirometry. Little is known about the determinants and natural history of non-communicable respiratory disease across the life course in Malawi. We strongly recommend that non-communicable respiratory disease should be a priority for future research in Malawi and that this would benefit from the use of methodologies standardised across studies. For example, it would be particularly useful to standardise diagnostic definitions and report all spirometry data to ATS/ERS standards. A specific consensus on the spirometry reference ranges used, or the development of locally appropriate specific reference ranges, is also needed. The substantial burden of chronic respiratory symptoms and abnormal spirometry data in Malawian children and adults is highly evident in our findings. Consequently, it is vital that we provide high quality, accessible and affordable care to this population, This has implications for Malawian policy- and decision-makers and our efforts to develop universal health coverage in Malawi. Although our systematic review and meta-analysis deliberately focused on Malawi, our findings are of generalisable relevance to the wider sub-Saharan African region.

\section{Authors' contributions}

Design: RN, HJ, JR, KM, ML

Acquisition of data: RN, HJ, ML

Analysis of data: RN, HJ, JM, SR, JR, KM, ML

Interpretation of data: RN, HJ, JM, SR, JM, HC, JR, KM, ML

All of the authors helped to write the manuscript and agreed for the final version to be published. All authors agree to be held accountable for all aspects of the research described herein

\section{Funding}

RN was funded by the Medical Research Council Doctoral Training Programme.

\section{Acknowledgements}

We thank the NIHR Global Health Research Unit on Lung Health and TB in Africa at LSTM - "IMPALA" for helping to make this work possible. IMPALA (Grant number 16/136/35) was commissioned by the National Institute for Health Research (NIHR) Global Health Research (GHR) using aid from the UK Government. The views expressed in this publication are those of the author(s) and not necessarily those of the NIHR or the Department of Health and Social Care

\section{Conflict of Interests}

There are no other conflicts to declare from the authors.

\section{References}

1. WHO. WHO Noncommunicable diseases- key facts: WHO; 2018 [cited 2019 Mar 19]. Available from: https://www.who.int/news-room/ fact-sheets/detail/noncommunicable-diseases.

2. Beaglehole R, Bonita R, Alleyne G, Horton R, Li L, Lincoln P, et al. UN high-level meeting on non-communicable diseases: addressing four questions. Lancet. 2011;378(9789):449-55. doi: https://doi. org/10.1016/S0140-6736(11)60879-9.

3. World Health Organization. Global action plan for the prevention and control for non-communicable diseases, 2013-2020; Geneva, Switzerland [cited 2019 Mar 19]. http://www.who.int/nmh/events/ ncd_action_plan/en/.

4. United Nations. Sustainable Devlopment Goal 3 New York: United Nations General Assembley [cited 2019 Mar 19]. Available from: https://sustainabledevelopment.un.org/sdg3.

5. Malawi MoH. The National Health Research Agenda. Lilongwe, Malawi; 2012. p. 14.

6. Soriano JB, Abajobir AA, Abate KH, Abera SF, Agrawal A, Ahmed $\mathrm{MB}$, et al. Global, regional, and national deaths, prevalence, disability-adjusted life years, and years lived with disability for chronic obstructive pulmonary disease and asthma, 1990-2015: a systematic analysis for the Global Burden of Disease Study 2015. The Lancet Respir Med. 2017;5(9):691-706. doi: https://doi.org/10.1016/ S2213-2600(17)30293-X

7. WHO. WHO Asthma Factsheet Geneva, Switzerland: World Health Organization; 2013 [cited 2019 Mar 19]. Available from: http://www. who.int/mediacentre/factsheets/fs307/en/.

8. Finney LJ, Feary J, Leonardi-Bee J, Gordon S, Mortimer K. Chronic obstructive pulmonary disease in sub-Saharan Africa: a systematic review [Review article]. The Int J Tuberc Lung Dis. 2013;17(5):583-9. 
doi: https://doi.org/10.5588/ijtld.12.0619

9. Adeloye D, Chua S, Lee C, Basquill C, Papana A, Theodoratou E, et al. Global and regional estimates of COPD prevalence: Systematic review and meta-analysis. J Glob Health. 2015;5(2). doi: doi: 10.7189/ jogh.05-020415

10. Network GA. The Global Asthma Report 2018; 2018 [cited 2019 Feb 14]. Available from: http://www.globalasthmareport.org/.

11. Pearce N, Aït-Khaled N, Beasley R, Mallol J, Keil U, Mitchell E, et al. Worldwide trends in the prevalence of asthma symptoms: phase III of the International Study of Asthma and Allergies in Childhood (ISAAC). Thorax. 2007;62(9):758-66. doi: http://dx.doi.org/10.1136/ thx.2006.070169

12. Buist AS, Vollmer WM, Sullivan SD, Weiss KB, Lee TA, Menezes $\mathrm{AM}$, et al. The burden of obstructive lung disease initiative (BOLD): rationale and design. COPD: J Chronic Obstr Pulm Dis. 2005;2(2):27783. doi: https://doi.org/10.1081/COPD-57610

13. Buist AS, McBurnie MA, Vollmer WM, Gillespie S, Burney $\mathrm{P}$, Mannino DM, et al. International variation in the prevalence of COPD (the BOLD Study): a population-based prevalence study. Lancet. 2007;370(9589):741-50. doi: https://doi.org/10.1016/S01406736(07)61377-4

14. Obaseki DO, Erhabor GE, Gnatiuc L, Adewole OO, Buist SA, Burney PG. Chronic Airflow Obstruction in a Black African Population: Results of BOLD Study, Ile-Ife, Nigeria. COPD. 2016;13(1):42-9. doi: 10.3109/15412555.2015.1041102.

15. Nightingale R, Lesosky M, Flitz G, Rylance SJ, Meghji J, Burney P, et al. Noncommunicable respiratory disease and air pollution exposure in Malawi (CAPS). A cross-sectional study. Am J Respir Crit Care Med. 2019;199(5):613-21. doi: https://doi.org/10.1164/rccm.2018050936OC

16. Meghji J, Nadeau G, Davis KJ, Wang D, Nyirenda MJ, Gordon $\mathrm{SB}$, et al. Noncommunicable lung disease in Sub-Saharan Africa. A Community-based cross-sectional study of adults in urban Malawi. Am J Respir Crit Care Med. 2016;194(1):67-76. doi: https://doi. org/10.1164/rccm.201509-1807OC

17. North CM, Kakuhikire B, Vořechovská D, Hausammann-Kigozi S, McDonough AQ, Downey J, et al. Prevalence and correlates of chronic obstructive pulmonary disease and chronic respiratory symptoms in rural southwestern Uganda: a cross-sectional, population-based study. J Glob Health. 2019;9(1):010434. doi: 10.7189/jogh.09.010434.

18. Siddharthan T, Grigsby M, Morgan B, Kalyesubula R, Wise RA, Kirenga B, et al. Prevalence of chronic respiratory disease in urban and rural Uganda. Bulletin of the World Health Organization. 2019;97(5):318.

19. Kossmeier M TU, Voracek M. Forest plots, funnel plots and visual funnel plot inference for meta-analysis. R package version 0.3.0 2019 [cited 2019 May 20]. Available from: https://CRAN.R-project.org/ package $=$ metaviz.

20. Jary HR, Aston S, Ho A, Giorgi E, Kalata N, Nyirenda M, et al. Household air pollution, chronic respiratory disease and pneumonia in Malawian adults: A case-control study. Wellcome Open Res. 2017;2:103. doi: 10.12688/wellcomeopenres.12621.1

21. Jary H, Mallewa J, Nyirenda M, Faragher B, Heyderman R, Peterson I, et al. Study protocol: the effects of air pollution exposure and chronic respiratory disease on pneumonia risk in urban Malawian adults-the Acute Infection of the Respiratory Tract Study (The AIR Study). BMC Pul Med. 2015;15(1):96.

22. Zverev Y. Prediction of peak expiratory flow rates in stunted children. The Central African J Med. 2001;47(3):74-8.

23. Cook J, Jefferis O, Matchere P, Mbale E, Rylance J. Sickle-cell disease in Malawian children is associated with restrictive spirometry: A cross-sectional survey. Inter J Tuberc Lung Dis. 2013;17(9):1235-8. doi: 10.5588/ijtld.12.0965.
24. Mwalukomo T, Rylance SJ, Webb EL, Anderson S, O'Hare B, van Oosterhout JJ, et al. Clinical characteristics and lung function in older children vertically infected with human immunodeficiency virus in Malawi. J Pediat Inf Dis Soc. 2016;5(2):161-9. doi: 10.1093/jpids/ piv045.

25. Lelijveld N, Kerac M, Seal A, Chimwezi E, Wells JC, Heyderman RS, et al. Long-term effects of severe acute malnutrition on lung function in Malawian children: A cohort study. Eur Respir J. 2017;49(4):1601301. doi: 10.1183/13993003.01301-2016.

26. Rylance S, Nightingale R, Naunje A, Mbalume F, Jewell C, Balmes $\mathrm{JR}$, et al. Lung health and exposure to air pollution in Malawian children (CAPS): a cross-sectional study. Thorax. 2019; 74(11):1070-7. doi: http://dx.doi.org/10.1136/thoraxjnl-2018-212945

27. Fullerton DG, Suseno A, Semple S, Kalambo F, Malamba R, White $\mathrm{S}$, et al. Wood smoke exposure, poverty and impaired lung function in Malawian adults. Inter J Tuber Lung Dis. 2011;15(3):391-8.

28. To T, Stanojevic S, Moores G, Gershon AS, Bateman ED, Cruz AA, et al. Global asthma prevalence in adults: findings from the crosssectional world health survey. BMC Public Health. 2012;12(1):204.

29. Jary HR, Kachidiku J, Banda H, Kapanga M, Doyle JV, Banda E, et al. Feasibility of conducting a randomised controlled trial of a cookstove intervention in rural Malawi. Inter J Tuber Lung Dis. 2014;18(2):240-7. doi: https://dx.doi.org/10.5588/ijtld.13.0485.

30. Manjomo RC, Mwagomb B, Ade S, Ali E, Ben-Smith A, Khomani $\mathrm{P}$, et al. Managing and monitoring chronic non-communicable diseases in a primary health care clinic, Lilongwe, Malawi. Public Health Action. 2016;6(2):60-5. doi: 10.5588/pha.16.0003.

31. Wang Q, Brenner S, Kalmus O, Banda HT, De Allegri M. The economic burden of chronic non-communicable diseases in rural Malawi: an observational study. BMC Health Serv Res. 2016;16:457. doi: https://dx.doi.org/10.1186/s12913-016-1716-8.

32. Banda HT, Thomson R, Mortimer K, Bello GAF, Mbera GB, Malmborg $\mathrm{R}$, et al. Community prevalence of chronic respiratory symptoms in rural Malawi: Implications for policy. PLoS ONE. 2017;12(12):e0188437. doi: 10.1371/journal.pone.0188437.

33. Das I, Jagger P, Yeatts K. Biomass cooking fuels and health outcomes for women in Malawi. EcoHealth. 2017;14(1):7-19. doi: 10.1007/s10393-016-1190-0.

34. Townend J, Minelli C, Mortimer K, Obaseki DO, Al Ghobain M, Cherkaski $\mathrm{H}$, et al. The association between chronic airflow obstruction and poverty in 12 sites of the multinational BOLD study. Eur Respir J. 2017;49(6):1601880. doi: 10.1183/13993003.01880-2016.

35. Cohen DB, Davies G, Malwafu W, Mangochi H, Joekes E, Greenwood S, et al. Poor outcomes in recurrent tuberculosis: More than just drug resistance? PloS One. 2019;14(5):e0215855.

36. Obaseki DO, Erhabor GE, Gnatiuc L, Adewole OO, Buist SA, Burney PG. Chronic airflow obstruction in a black African population: results of BOLD study, Ile-Ife, Nigeria. COPD: J Chronic Obstr Pulm Dis. 2016;13(1):42-9. doi: https://doi.org/10.3109/15412555.2015.104 1102

37. van Gemert F, Kirenga B, Chavannes N, Kamya M, Luzige S, Musinguzi $\mathrm{P}$, et al. Prevalence of chronic obstructive pulmonary disease and associated risk factors in Uganda (FRESH AIR Uganda): a prospective cross-sectional observational study. Lancet Glob Health. 2015;3(1):e44-e51. doi: https://doi.org/10.1016/S2214- (14)70337-7 